\title{
Piperlongumine induces apoptotic and autophagic death of the primary myeloid leukemia cells from patients via activation of ROS-p38/JNK pathways
}

\author{
Xin-xin XIONG ${ }^{1, \#}$, Ju-mei LIU ${ }^{1, \#}$, Xin-yao QIU ${ }^{1}$, Feng PAN ${ }^{1,2}$, Shang-bin YU ${ }^{1}$, Xiao-qian CHEN ${ }^{1, *}$ \\ ${ }^{1}$ Department of Pathophysiology, School of Basic Medicine; Key Laboratory of Neurological Diseases, Ministry of Education; Institute \\ of Brain Research, Huazhong University of Science and Technology, Wuhan 430030, China; ${ }^{2}$ Department of Urology, Union Hospital, \\ Tongji Medical College, Huazhong University of Science and Technology, Wuhan 430022, China
}

Aim: To investigate the effects of piperlongumine (PL), an anticancer alkaloid from long pepper plants, on the primary myeloid leukemia cells from patients and the mechanisms of action.

Methods: Human BM samples were obtained from 9 patients with acute or chronic myeloid leukemias and 2 patients with myelodysplastic syndrome (MDS). Bone marrow mononuclear cells (BMMNCs) were isolated and cultured. Cell viability was determined using MTT assay, and apoptosis was examined with PI staining or flow cytometry. ROS levels in the cells were determined using DCFH-DA staining and flow cytometry. Expression of apoptotic and autophagic signaling proteins was analyzed using Western blotting.

Results: PL inhibited the viability of BMMNCs from the patients with myeloid leukemias (with IC ${ }_{50}$ less than $20 \mu \mathrm{mol} / \mathrm{L}$ ), but not that of BMMNCs from a patient with MDS. Furthermore, PL (10 and $20 \mu \mathrm{mol} / \mathrm{L})$ induced apoptosis of BMMNCs from the patients with myeloid leukemias in a dose-dependent manner. PL markedly increased ROS levels in BMMNCs from the patients with myeloid leukemias, whereas pretreatment with the antioxidant N-acetyl-L-cysteine abolished PL-induced ROS accumulation and effectively reduced PL-induced cytotoxicity. Moreover, PL markedly increased the expression of the apoptotic proteins (Bax, Bcl-2, and caspase-3) and autophagic proteins (Beclin-1 and LC3B), and phosphorylation of p38 and JNK in BMMNCs from the patients with myeloid leukemias, whereas pretreatment with the specific p38 inhibitor SB203580 or the specific JNK inhibitor SP600125 partially reversed PL-induced ROS production, apoptotic/autophagic signaling activation and cytotoxicity.

Conclusion: Piperlongumine induces apoptotic and autophagic death of the primary myeloid leukemia cells from patients via activation of ROS-p38/JNK pathways.

Keywords: piperlongumine; ayurvedic medicine; myeloid leukemia; myelodysplastic syndrome; apoptosis; autophagy; R0S; p38; JNK; N-acetyl-L-cysteine; SB203580; SP600125

Acta Pharmacologica Sinica (2015) 36: 362-374; doi: 10.1038/aps.2014.141; published online 26 Jan 2015

\section{Introduction}

Myeloid leukemias (MLs), including acute and chronic myeloid leukemia (AML and CML), are clonal bone-marrow diseases characterized by the pathological proliferation of abnormal white blood cells. AML, the most frequent type of blood cancer in adults, is an aggressive and fatal disease caused by the increased proliferation and blocked differentiation of myeloid blast cells ${ }^{[1]}$. CML, which accounts for approximately $15 \%-20 \%$ of all leukemias arising in adulthood,

\footnotetext{
"These authors contributed equally to this paper.

* To whom correspondence should be addressed.

E-mail chenxq@mails.tjmu.edu.cn

Received 2014-08-30 Accepted 2014-11-13
}

is characterized by the overproduction and accumulation of mature but functionally impaired myeloid cells and carries the risk of progressing into an accelerated phase and a blast crisis that are refractory to the current treatments ${ }^{[2]}$. Chemotherapy plus hematopoietic stem-cell transplantation (SCT) have greatly improved the overall survival time of AML patients $^{[3,4]}$; however, at this time, approximately $30 \%-40 \%$ of AML patients do not have access to SCT or are resistant to the current chemotherapeutics ${ }^{[5,6]}$. Moreover, high-dose chemotherapy is highly toxic and causes severe side effects, such as skin rash, edema, muscular cramps or pustular eruptions ${ }^{[7]}$. Clearly, more selective therapeutic drugs for ML patients must be developed.

Piper longum L, ie, the long pepper plant, has been used in 
traditional Ayurvedic medicine to treat gastrointestinal and respiratory diseases for a thousand years ${ }^{[8]}$. Piperlongumine (PL) is the major effective alkaloid of long pepper plants and has a well-characterized structure $\left(\mathrm{C}_{17} \mathrm{H}_{19} \mathrm{NO}_{5}\right)^{[9]}$. Recently, the screening studies by two independent research groups showed that PL was highly selectively cytotoxic to cancer cells $^{[10,11]}$, strongly suggesting that PL is a promising drug for cancer therapy. Raj et $a l^{[10]}$ reported that PL selectively killed various types of cancer cells and oncogene-transformed cells but not normal cells by inducing the accumulation of reactive oxygen species (ROS). The mechanisms underlying this phenomenon might involve the preferential binding of PL with ROS-clearance proteins, such as glutathione S-transferase pi 1 (GSTP1) or carbonyl reductase 1 (CBR1), thereby representing a novel cancer therapy strategy of targeting ROS responses. Recently, the anticancer effects of PL have been demonstrated in more cancer cell lines, and multiple mechanisms have been proposed to explain the activity of PL, including the induction of apoptosis ${ }^{[12]}$, autophagic cell death ${ }^{[13]}$ or cell-cycle arrest ${ }^{[14]}$. The downstream signaling pathways activated by ROS accumulation in cancer cells include the p38 mitogen-activated protein kinase (p38 MAPK) pathway, the c-Jun N-terminal kinase (JNK) pathway, the extracellular signal-regulated kinase (Erk) pathway and the nuclear factor $\mathrm{KB}(\mathrm{NF} \mathrm{KB})$ pathway ${ }^{[12,15-17]}$.

Previous studies examined only the cytotoxic effects of PL in cancer cell lines. Whether PL could effectively kill primary cancer cells obtained from patients is currently unknown. Because primary cancer cells best represent cancer cells within patients, the results obtained using primary cancer cells are pivotal to translating the anticancer effects of PL from the laboratory to the clinic. Therefore, we investigated the cytotoxic effect of PL and the underlying mechanisms using primary myeloid leukemia cells obtained from patients suffering from AML and CML. Our results demonstrated that PL was effective in killing myeloid leukemia cells obtained from patients and that multiple mechanisms were involved in the action of PL.

\section{Materials and methods}

\section{Primary cultures of human myeloid leukemia cells}

Bone marrow (BM) samples were obtained from patients admitted to Tongji Hospital, Huazhong University of Science and Technology. All of the patients with newly diagnosed or initially relapsed AML or CML met the World Health Organization's criteria for the diagnosis of AML or CML, and the diagnosis was confirmed through a formal histopathological review (the patients' information is shown in Table 1). The human BM samples were obtained following informed consent, in accordance with a clinical protocol that was approved by Institutional Review Board of Tongji Hospital, HUST. Among 11 patients (for whom no selection criteria was applied), 9 suffered from ML ( 1 with the M1 subtype of AML; 3 with the M2 subtype of AML; 2 with the M5 subtype of AML; 3 with CML) and 2 with myelodysplastic syndrome (MDS) (Table 1 and Figure 1). The bone marrow mononuclear cells (BMMNCs) were isolated using gradient centrifugation. After lysing the red blood cells using the Red Blood Cell Lysis Buffer (Wuhan Goodbio Technology, Wuhan, China), the white cells were resuspended and washed twice using phosphate-buffered saline (PBS). The cell viability rate was greater than $90 \%$, as determined using trypan blue staining. Finally, the BMMNCs were cultured in 35-mm dishes at a density of $2 \times 10^{6}$ cells $/ \mathrm{mL}$ in Roswell Park Memorial Institute 1640 (RPMI 1640) medium (Gibco Invitrogen, Grand Island, NY, USA), supplemented with $20 \%$ fetal bovine serum (FBS, Gibco Invitrogen) and $100 \mathrm{U} / \mathrm{mL}$ penicillin-streptomycin (Gibco Invitrogen). The cells were used for drug-treatment experiments $24 \mathrm{~h}$ after subculturing and were then utilized in other experiments.

\section{Treatment with piperlongumine and other drugs}

Piperlongumine (Sigma-Aldrich, St Louis, MO, USA) was dissolved in dimethyl sulfoxide (DMSO) to prepare a $50 \mathrm{mmol} / \mathrm{L}$ stock concentration. The final concentration of DMSO was less than $0.1 \%$. N-acetyl-L-cysteine (NAC, antioxidant, Sigma-

Table 1. Clinicopathologic features of primary diseases information in 11 cases of donor cell-derived leukemia/myelodysplastic neoplasms.

\begin{tabular}{|c|c|c|c|c|c|c|c|}
\hline \# & Sex & $\begin{array}{l}\text { Age } \\
\text { (year) }\end{array}$ & $\begin{array}{c}\text { Diagnosis } \\
\text { FAB subtypes }\end{array}$ & $\begin{array}{r}\text { Status } \\
\left(\times 10^{9} / \mathrm{L}\right)\end{array}$ & WBC & Source & Cytogenetics \\
\hline 1 & M & 26 & M1 & Newly diagnosed & 249.65 & BM & $46, X Y, N^{[20]}$ \\
\hline 3 & $\mathrm{~F}$ & 24 & CML & Newly diagnosed & 301.48 & BM & $46, x X, t(9 ; 22)(q 34 ; q 11)^{[60]}$ \\
\hline 4 & $\mathrm{~F}$ & 41 & M5 & Newly diagnosed & 90.69 & BM & $47, \mathrm{XX}, \mathrm{t}(10 ; 11)(\mathrm{p} 12 ; \mathrm{q} 23)+\mathrm{mar}^{[7]} / 46, \mathrm{XX}^{[3]}$ \\
\hline 7 & $\mathrm{~F}$ & 47 & M2 & Relapse & 5.44 & BM & No split phase \\
\hline 8 & M & 52 & CML & Newly diagnosed & 194.59 & BM & $46, \mathrm{XY}, \mathrm{t}(9 ; 22)(\mathrm{q} 34 ; \mathrm{q} 11)^{[38]}$ \\
\hline 9 & $\mathrm{~F}$ & 62 & $\mathrm{CML}$ & Newly diagnosed & 123.7 & BM & $46, X^{[20]}$ \\
\hline 10 & $\mathrm{~F}$ & 66 & MDS-RAEB2 & Newly diagnosed & 11.97 & BM & $\begin{array}{l}\text { 46, XX, del(2)(p11), del(3)(p12), del(3)(p26), del(3)(q13), } \\
\text { del(4)(q31), del(6)(p23), del(7)(q22q34), -10, del(12) } \\
\text { (p12), del(13)(q12q14), +15, -16, -21, +mar[cp10] }\end{array}$ \\
\hline
\end{tabular}



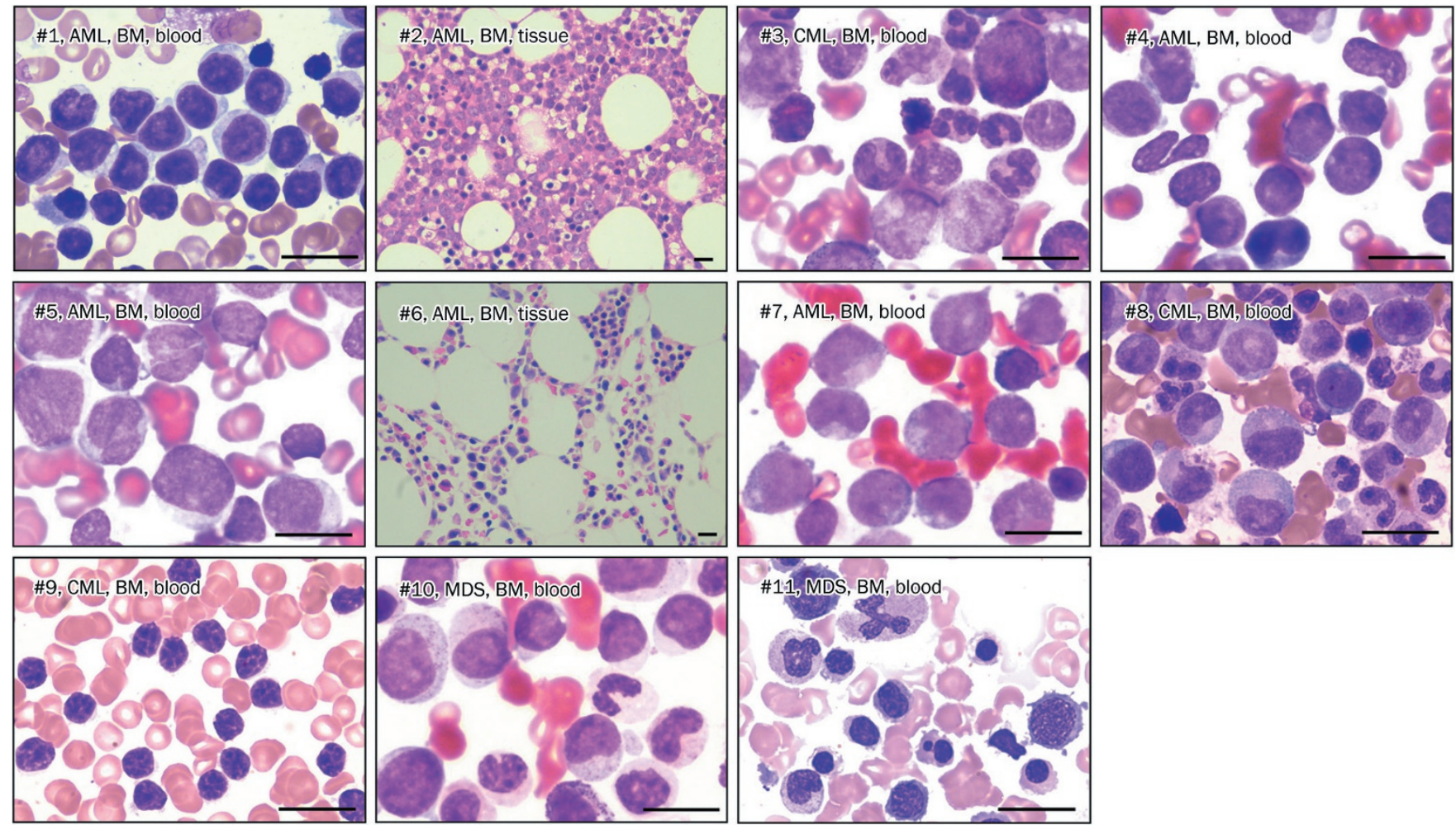

Figure 1. Morphology of bone marrow cells derived from patients. Bone marrow (BM), blood or tissue samples from freshly diagnosed or first-relapsed patients with AML, CML, or MDS were stained using Giemsa or H\&E dyes. The representative micrographs show the morphologies of BM and blood cells or tissue as viewed under a light microscope (magnification of $1000 \times$ for BM and blood samples and $200 \times$ for BM tissues. Bar=20 $\mu$ m).

Aldrich, St Louis, MI, USA) was used at $3 \mathrm{mmol} / \mathrm{L}$, whereas SB203580 (P38 pathway-specific inhibitor, Cell Signaling Technology, Danvers, MA, USA) and SP600125 (JNK pathwayspecific inhibitor, Cell Signaling Technology) were used at $10 \mu \mathrm{mol} / \mathrm{L}$. NAC, SB203580, and SP600125 were added $1 \mathrm{~h}$ before PL-treatment.

\section{Cell viability assay}

The 3-(4,5-dimethylthiazol-2-yl)-2,5-diphenyltetrazolium bromide (MTT, Sigma-Aldrich) assay was used to determine the cell viability rate, as reported previously ${ }^{[12]}$. Briefly, primary human BMMNCs were seeded in 96-well plates (4000 cells/ well) and incubated for $24 \mathrm{~h}$ under normal culture conditions. The cells were treated with drugs in six parallel wells for the designated periods and then were treated with $20 \mathrm{mg} / \mathrm{mL}$ MTT. The cell viability rate was determined from the intensity of the optical absorption at $490 \mathrm{~nm}$ using a microplate reader (Synergy $^{\mathrm{TM}}$ 2, Biotek, Winooski, VT, USA).

\section{Apoptosis assay}

The annexin V-based apoptosis assay was performed as described $^{[12]}$. Cultured BMMNCs cells were treated with 0 , 10 , and $20 \mu \mathrm{mol} / \mathrm{L}$ PL alone or together with NAC for $24 \mathrm{~h}$ and then were co-stained with anti-annexin V-FITC and propidium iodide (PI) according to the manufacturer's instructions (Invitrogen, Life Technologies Inc, Carlsbad, CA, USA). After $24 \mathrm{~h}$ of PL treatment, the cells were harvested, washed using ice-cold PBS, resuspended in $195 \mu \mathrm{L}$ of binding buffer and incubated with $5 \mu \mathrm{L}$ of anti-annexin V-FITC for $10 \mathrm{~min}$ at room temperature in the dark. The samples were resuspended in annexin V-FITC binding buffer and were counterstained using PI. Untreated cells were used as the negative control. After being stained, the cells were maintained in an ice bath for 10 min in the dark prior to flow cytometry (FCM) (Becton Dickinson, Franklin Lakes, NJ, USA) analysis.

\section{Determination of the intracellular ROS content}

To assess the intracellular production of ROS, the primary BMMNCs were treated with PL for $3 \mathrm{~h}$ alone or together with other drugs. The cells were incubated in $10 \mu \mathrm{mol} / \mathrm{L}$ $2^{\prime}-, 7^{\prime}$-dichloro-fluorescin diacetate (DCFH-DA; SigmaAldrich). The DCFH-DA-fluorescence intensities (representing the intracellular ROS levels) were determined using conventional fluorescence microscopy (Olympus, Tokyo, Japan) or using FCM. The average fluorescence intensities of DCFH-DA in the cells in 9 randomly chosen fields were analyzed using Image-Pro Plus software (Media Cybernetics, Silver Spring, MD, USA).

\section{Western blotting analyses}

The Western blotting analyses were performed as previously described ${ }^{[18]}$. The total soluble proteins were extracted from the primary BMMNCs using radio-immunoprecipitation assay (RIPA) lysis buffer (Applygen Technologies Incorporation, 
Beijing, China) containing phenylmethanesulfonyl fluoride (Sigma-Aldrich), and equal amounts of total protein were loaded on a $12 \%$ denaturing polyacrylamide gel. The blotted membranes were blocked using $5 \%(w / v)$ nonfat dried milk in Tris-buffered saline (TBS) and then were incubated with primary antibodies directed against $\beta$-actin, p-p38 Thr180/182, p38, p-JNK Thr183/185, JNK, Bcl-2, Bax, caspase-3, LC3B (1:1000, Cell Signaling Technology) and Beclin-1 (1:1000, Santa Cruz Biotechnology, Santa Cruz, CA, USA). After incubation with IRDye $800 \mathrm{CW}$ - or IRDye $680 \mathrm{CW}$-conjugated goat antirabbit or anti-mouse IgG antibodies (LI-COR Bioscience, Lincoln, NE, USA), the labeled bands were visualized and quantified using an Odyssey Infrared Imaging System (LI-COR Bioscience).

\section{Statistical analysis}

All experiments were repeated independently at least three times. The quantitative results are expressed as the mean \pm SEM. The significance of the differences between the groups was determined using a one-way analysis of variance (ANOVA) and the Student-Newman-Keuls test. $P$ values of less than 0.05 were considered significant. All of the results were analyzed using SPSS (Statistical Package for the Social Sciences) 13.0 statistical software (SPSS, Chicago, IL, USA).

\section{Results}

Piperlongumine efficiently killed primary human myeloid leukemia cells obtained from patients with ML but not MDS via inducing apoptosis

To translate the anti-cancer effects of PL observed in cell lines to clinical applications, we tested the cytotoxic effect of PL in primary BMMNCs obtained from 11 patients ( 9 with ML and 2 with MDS). All patients were randomly selected, and their clinical information is shown in Table 1. The morphologies of the bone marrow (BM) blood cells or tissue cells of the patients are shown in Figure 1 (\#1, \#3, \#4, \#5, \#7-\#11, Giemsa staining; \#2 and \#6, H\&E staining). The structure of PL is shown in Figure 2A. The cytotoxic effect of PL in primary BMMNCs is evaluated upon $24 \mathrm{~h}$ of $\mathrm{PL}$ treatment (Figure 2B-2D). The MTT assay clearly showed that PL effectively reduced the viability of the BMMNCs obtained from all 9 of the patients with ML (\#1-\#9) in a dose-dependent manner. However, PL did not reduce the viability of BMMNCs obtained from the patient with MDS (\#10) (Figure 2B). These results strongly indicated that PL selectively killed the myeloid leukemia cells among the patient's BMMNCs. Notably, PL exerted a more potent cytotoxic effect in BMMNCs obtained from patients \#1, $\# 2$ and \#5, suggesting that a better therapeutic effect might be achieved in a subgroup of ML patients (3/9). The $\mathrm{IC}_{50}$ of PL in BMMNCs was less than $20 \mu \mathrm{mol} / \mathrm{L}$ (Figure 2B). We then further confirmed that PL-reduced viability of BMMNCs was due to cell death. PI staining clearly revealed that cell death was significantly increased at $24 \mathrm{~h}$ of PL treatment at 10 (PL 10) or $20 \mu \mathrm{mol} / \mathrm{L}$ (PL 20), in a dose-dependent manner (Figure 2C). Treatment with PL at $20 \mu \mathrm{mol} / \mathrm{L}$ induced the death of approximately $40 \%$ of the BMMNCs from patient \#3 as deter- mined using PI staining (Figure 2C), consistent with the results of the MTT assay (Figure 2B). We next examined whether PL induced the apoptosis of BMMNCs using FCM analysis after annexin V/PI double staining. The cells in the quadrant 2 (Q2) and Q4 with a higher intensity of annexin V staining represented apoptotic cells (Figure 2D). Our results clearly showed that the percentage of total apoptotic cells $(\mathrm{Q} 2+\mathrm{Q} 4)$ among the BMMNCs obtained from patient \#1 (3.8\%, DMSO vs $83.3 \%$, PL $20 \mu \mathrm{mol} / \mathrm{L})$ and in those from patient \#2 $(32.2 \%$, DMSO vs $56.4 \%$, PL $20 \mu \mathrm{mol} / \mathrm{L}$ ) was greatly increased after $24 \mathrm{~h}$ of PL treatment. The percentage of apoptotic cells among the PL-treated BMMNCs obtained from patient \#1 (approximately $80 \%$, Figure 2D) was similar to the percent reduction of viability of these cells (approximately $80 \%$, Figure 2B), suggesting that apoptosis was the predominant cause of cell death in this sample. In the BMMNCs from patient \#2, however, PL treatment resulted in $24.2 \%$ apoptotic cells, only partially accounting for the effect of PL on the viability of these cells (approximately $80 \%$, Figure 2B), indicating that non-apoptotic cell death was also induced by PL.

Piperlongumine induced ROS accumulation in primary human myeloid leukemia cells

PL is considered a cancer cell-specific ROS inducer ${ }^{[10]}$, and previous studies have demonstrated that PL induced ROS accumulation in various cancer cell lines ${ }^{[19-21]}$. We determined the level of intracellular ROS in PL-treated BMMNCs using the fluorescent ROS indicator DCFH-DA. Statistical analysis clearly demonstrated that the intensity of DCFH-DA fluorescence (representing the ROS level) in the primary BMMNCs (obtained from patient \#3) was significantly increased at $24 \mathrm{~h}$ of PL treatment, in a dose-dependent manner (PL 0, 10, and $20 \mu \mathrm{mol} / \mathrm{L}$ ) (Figure 3A). The PL-induced production of ROS in primary BMMNCs (obtained from patients \#1 and \#2) was further evaluated using FCM (Figure 3B and 3C). The intensity of DCFH-DA fluorescence in primary BMMNCs obtained from patients \#1 (Figure 3B) and \#2 (Figure 3C) was clearly increased at $24 \mathrm{~h}$ of treatment using PL at 10 or $20 \mu \mathrm{mol} / \mathrm{L}$, as demonstrated by the rightward shift (along the $x$-axis) of the peak of DCFH-DA fluorescence in these cell populations. Taken together, these results demonstrated that PL induced ROS accumulation in BMMNCs.

Piperlongumine induced cell death or apoptosis in primary human myeloid leukemia cells via ROS-dependent and -independent mechanisms

We then tested whether PL killed primary human BMMNCs via inducing ROS accumulation. Treatment with the antioxidant NAC completely abolished PL-induced cell death, as determined using PI staining of BMMNCs obtained from patient \#3 (Figure 4A), suggesting that PL induced cell death mainly via a ROS-dependent mechanism. Next, we examined whether NAC pretreatment reduced the rate of PL-induced apoptosis of primary BMMNCs. NAC pretreatment strongly reduced but did not inhibit the PL-induced apoptosis in the BMMNCs obtained from patient \#1 (83.3\% in the PL 20 
A<smiles>COc1cc(/C=C/C(=O)N2CCC=CC2=O)cc(OC)c1OC</smiles>

Piperlongumine (PL)
B

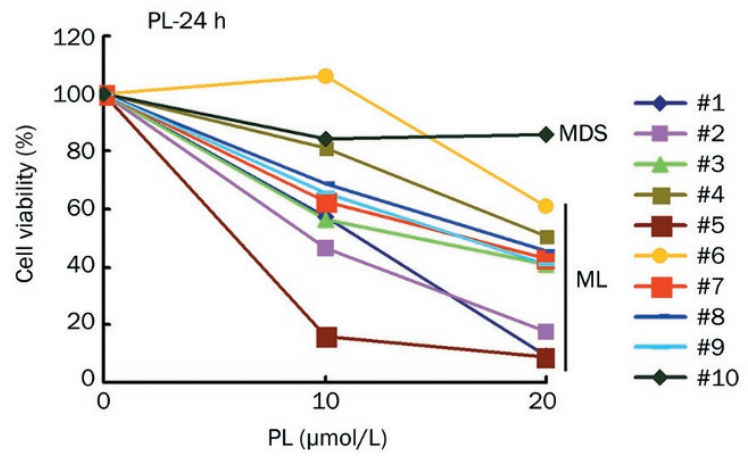

C $\# 3, \mathrm{PL}-24 \mathrm{~h}, \mathrm{PI}$
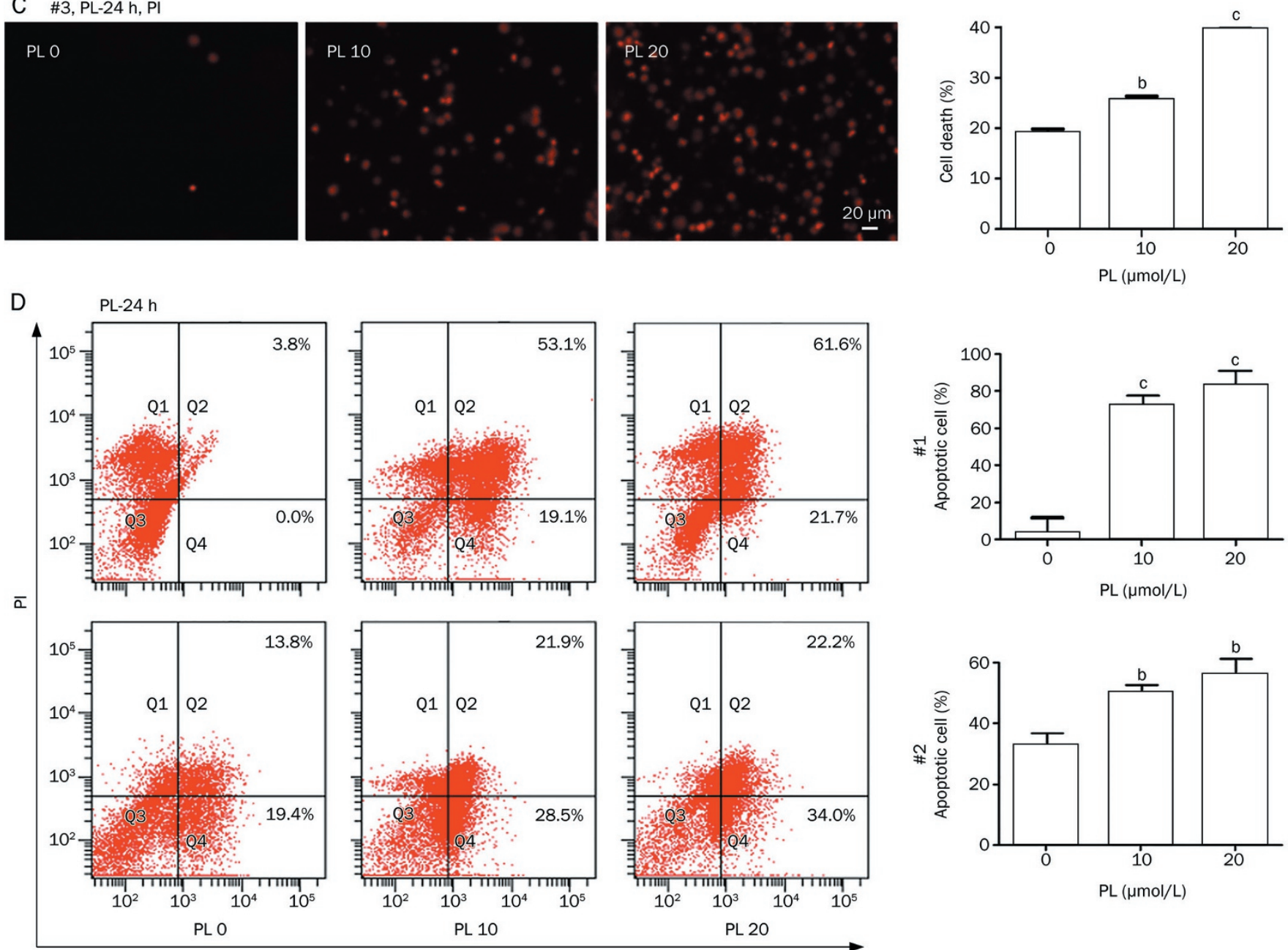

Annexin V-FITC

Figure 2. Piperlongumine effectively killed primary human myeloid leukemia cells via inducing cell death or apoptosis. (A) The structure of piperlongumine. (B) Viability of primary human BMMNCs after PL treatment. BMMNCs purified from the BM and blood of patients were cultured in 96well plates at a density of $2 \times 10^{4} / \mathrm{mL}$. The cultured BMMNCs were then treated with PL at various concentrations $(0,10$, or $20 \mu \mathrm{mol} / \mathrm{L})$ for $24 \mathrm{~h}$. Cell viability was determined using the MTT assay. (C) PL-induced cell death in BMMNCs. Primary human BMMNCs from patient \#3 were treated with PL at 0 , 10, or $20 \mu \mathrm{mol} / \mathrm{L}$ for $24 \mathrm{~h}$. Cell death was determined using PI staining. The left panels show representative micrographs of PI stained cells. The right panel shows the results of the statistical analysis $(n=3)$. ${ }^{b} P<0.05$ and ${ }^{\circ} P<0.01$ vs PL 0 . (D) PL-induced apoptosis in BMMNCs. Primary BMMNCs from patients \#1 and \#2 were treated with PL at 0, 10, or $20 \mu \mathrm{mol} / \mathrm{L}$ for $24 \mathrm{~h}$ before Pl/annexin V-FITC double-fluorescence staining. The cells in Q2 and Q4 represent apoptotic cells. The right panel shows the results of the statistical analysis $(n=3)$. ${ }^{b} P<0.05$ and ${ }^{c} P<0.01$ vs $P L 0$.

group vs $44.8 \%$ in the PL 20+NAC group) and those obtained from patient \#2 (56.2\% in the PL 20 group vs 39.5\% in the PL
20+NAC group) (Figure 4B).

Consistent with the effect of NAC of reducing the level 
A \#3, PL-3 h, DCFH-DA
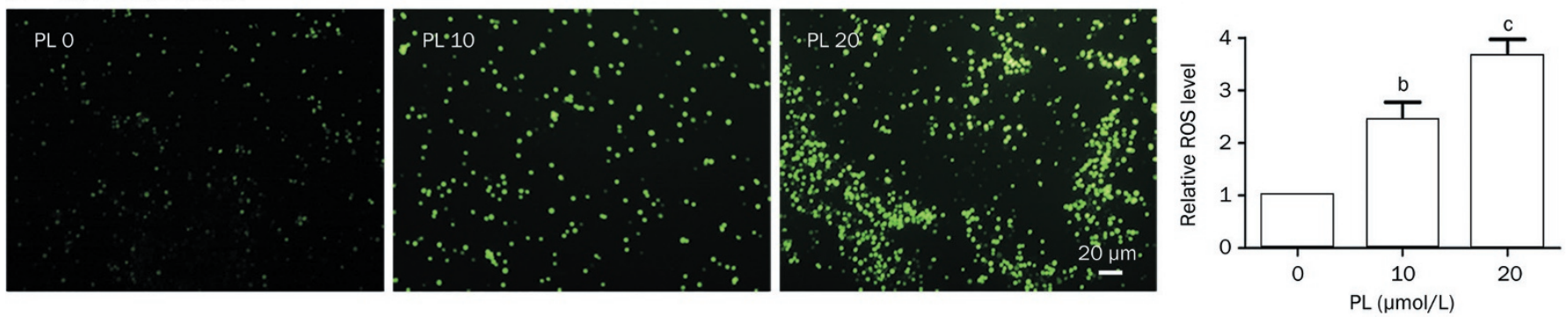

B

$\# 1$, PL-3 h
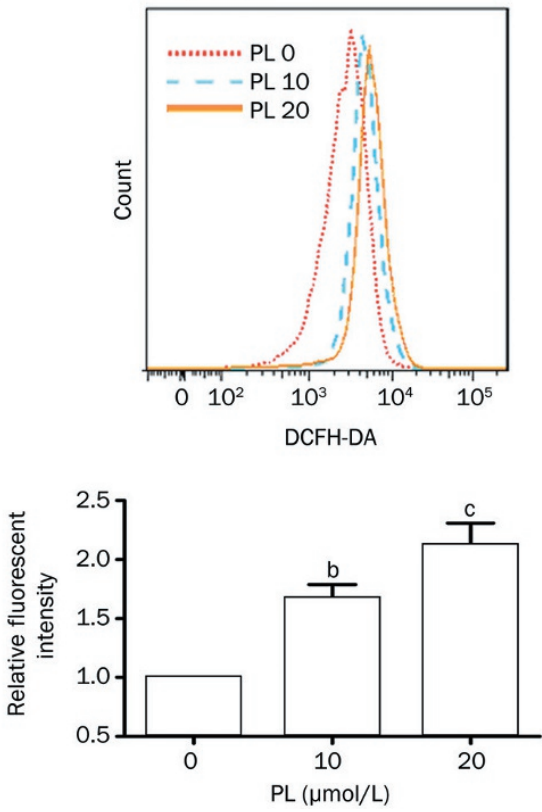

C
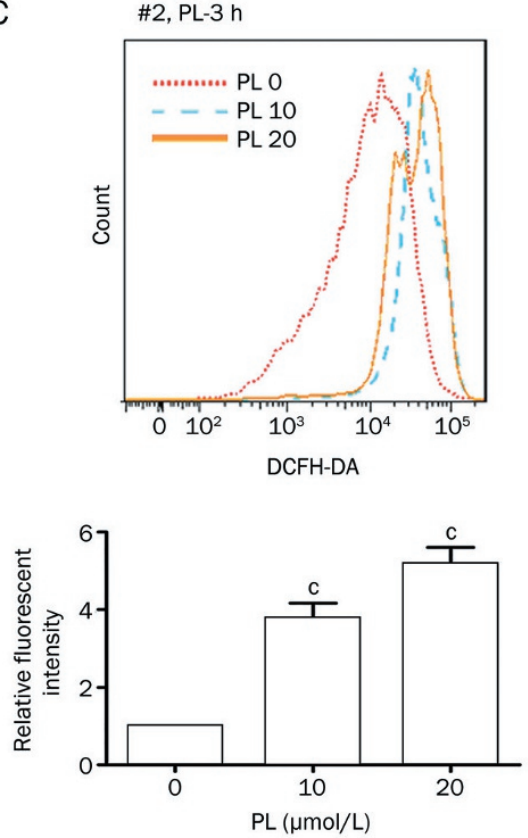

Figure 3. Piperlongumine induced ROS accumulation in primary human myeloid leukemia cells. (A) Increased ROS content in PL-treated primary BMMNCs. Primary BMMNCs from patients \#3 was treated with PL at 0, 10, or $20 \mu \mathrm{mol} / \mathrm{L}$ for $3 \mathrm{~h}$ and then were stained using DCFH-DA. The left panels show representative micrographs of cells exhibiting DCFH-DA fluorescence. The right panel shows the results of the statistical analysis of the relative intracellular ROS levels (represented by the mean intensity of DCFH-DA fluorescence) ( $n=3$ ). ${ }^{b} P<0.05$ and ${ }^{c} P<0.01$ vs PL 0 . (B, C) ROS accumulation in PL-treated primary BMMNCs obtained from patient \#1 (B) or \#2 (C). The DCFH-DA fluorescence of the cells was evaluated using FCM. The upper panels show the merged DCFH-DA fluorescence curves of BMMNCs treated with PL at 0,10 , and $20 \mu \mathrm{mol} / \mathrm{L}$. The fluorescence intensities of DCFH-DA were greatly increased after $3 \mathrm{~h}$ of PL treatment at 10 or $20 \mu \mathrm{mol} / \mathrm{L}$, as demonstrated by the rightward shift of the peak of DCFH-DA fluorescence of the cell population (along the $x$-axis). The $x$-axis represents the fluorescence intensity and the $y$-axis represents the number of cells. The mean DCFH-DA fluorescence intensity (lower panel) was determined using FlowJo 7.6 software. ${ }^{\mathrm{b}} P<0.05$ and ${ }^{\mathrm{c}} P<0.01$ vs PL 0 .

of PL-induced cell death or apoptosis of primary human BMMNCs, statistical analysis of the DCFH-DA fluorescence levels of these cells demonstrated that NAC pretreatment significantly reduced the level of PL-induced ROS accumulation in the BMMNCs obtained from patient \#3 (Figure 4C). However, PL and NAC had no effect on the intracellular ROS levels of BMMNCs obtained from an MDS patient (patient \#11, Figure 4C), suggesting that PL selectively killed myeloid leukemia cells via ROS-dependent mechanisms. FCM analysis showed that the mean intensities of DCFH-DA fluorescence in PL-treated primary BMMNCs obtained from patients \#1 (Figure 4D) and \#2 (Figure 4E) were clearly reduced by NAC pretreatment (PL 20+NAC), as demonstrated by the leftward shift of the peak of DCFH-DA fluorescence in these cell popu- lations. Taken together, the results indicated that PL induced cell death or apoptosis via ROS-dependent as well as ROSindependent mechanisms.

Piperlongumine activated apoptotic and autophagic cell-death pathways in primary human myeloid leukemia cells via ROS accumulation or $\mathrm{p} 38 / \mathrm{JNK}$ activation

We next explored the possible mechanisms underlying the cytotoxic effect of PL on primary BMMNCs. Because PL induced apoptosis in primary BMMNCs (Figure 2D), we evaluated the level of expression of Bcl-2 and Bax proteins, the two major members of the Bcl-2 family that gate-control mitochondria-mediated apoptotic cell death. Western blotting analysis showed that the level of Bax expression was increased upon 

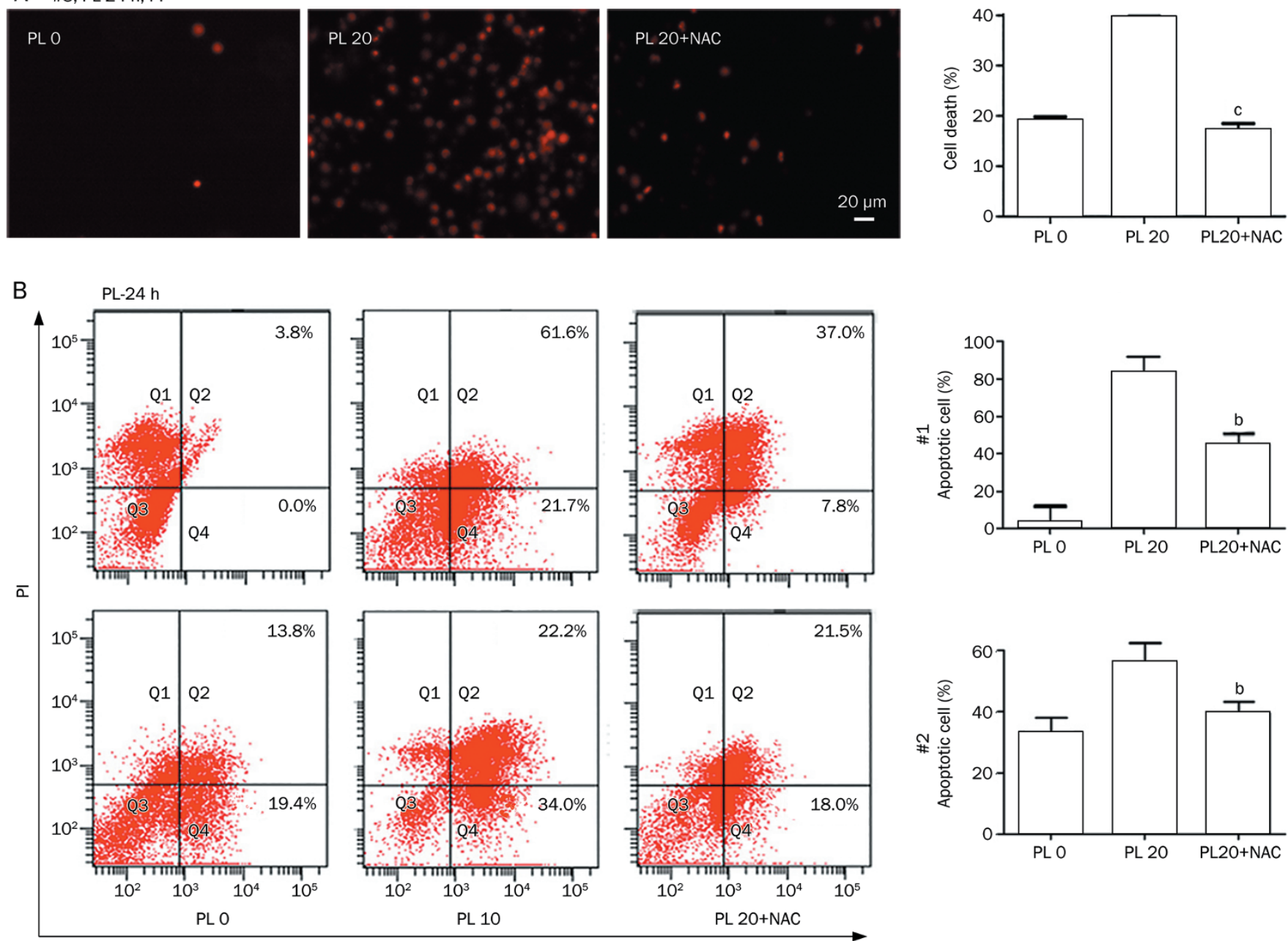

Figure 4A-4B. Piperlongumine induced cell death or apoptosis in primary human myeloid leukemia cells via ROS accumulation. (A) Treatment with the antioxidant NAC reduced the extent of PL-induced cell death, as demonstrated using PI staining of primary human BMMNCs obtained from patient \#3. The left panels show representative micrographs of Pl-stained cells. The right panel shows the results of the statistical analysis $(n=3)$. ${ }^{c} P<0.01 \mathrm{vs}$ PL 20. (B) NAC treatment reduced the extent of PL-induced apoptotic cell death. Primary BMMNCs obtained from patients \#1 and \#2 were treated with $\mathrm{PL}(20 \mu \mathrm{mol} / \mathrm{L})$ alone or in combination with NAC (3 mmol/L) for $24 \mathrm{~h}$ before Pl/annexin V-FITC double staining and FCM were performed. The cells in Q2 plus Q4 represent apoptotic cells. The right panel shows the results of the statistical analysis $(n=3) .{ }^{\mathrm{b}} P<0.05$ vs PL 20.

treatment with PL at 10 or $20 \mu \mathrm{mol} / \mathrm{L}$ (Figure 5A). In contrast, the level of Bcl-2 (a key factor in controlling mitochondrialmembrane permeability) expression was greatly reduced upon $\mathrm{PL}$ treatment (Figure 5A). The ratio of $\mathrm{Bax} / \mathrm{Bcl}-2$ was greatly increased in primary BMMNCs upon PL treatment. Consistent with the increased Bax/Bcl-2 ratio in PL-treated leukemia cells, the level of pro-caspase-3 was evidently decreased, suggesting that pro-caspase- 3 was cleaved upon PL treatment (Figure 5A). NAC treatment reduced the content of Bax, increased the content of Bcl-2 and slightly increased the procaspase-3 content in PL-treated leukemia cells (Figure 5A). In addition, we tested the role of the p38 and JNK signaling pathways in PL-induced cell death because p38 and JNK are the two canonical ROS-activated signaling pathways ${ }^{[22,23]}$. It was clear that suppressing the activation of p38 (SB203580, SB) or JNK (SP600125, SP) reduced the level of Bax and increased the level of pro-caspase- 3 in PL-treated BMMNCs (Figure $5 \mathrm{~A}$ ). The evidence that apoptosis (of BMMNCs obtained from patient \#2, Figure 2D) only partially accounted for the PLinduced cell death (of BMMNCs obtained from patient \#2, Figure 4B), PL-treated BMMNCs appeared to undergo other types of cell death. Autophagy is a common stress response of cancer cells, and the overactivation of autophagic signaling causes programmed cell death, ie, autophagic cell death ${ }^{[24,25]}$. Western blotting analysis showed that both Beclin-1 and LC3B, two molecular markers of autophagic cell death, were affected by PL treatment of primary BMMNCs, with the level of expression of the former being increased and the level of activation of the latter (ie, converted from the LC3-I form to the LC3-II form) being increased in primary BMMNCs at 
C \#3, PL-3 h, DCFH-DA
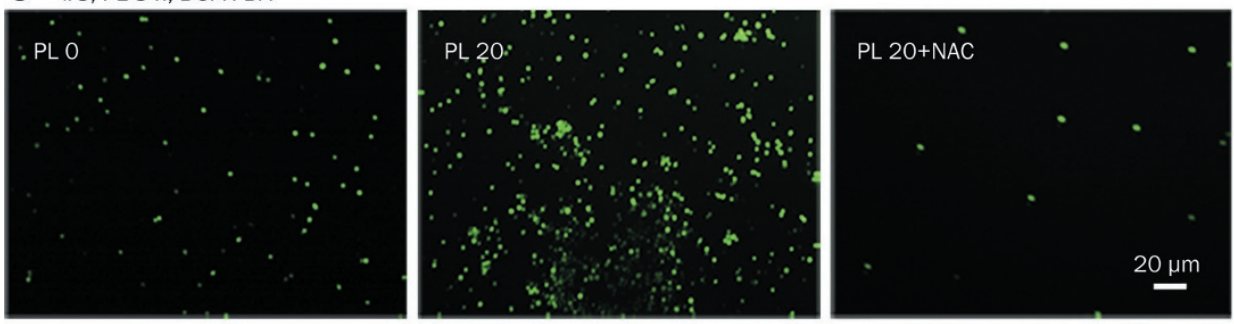

\#11, PL-3 h, DCFH-DA
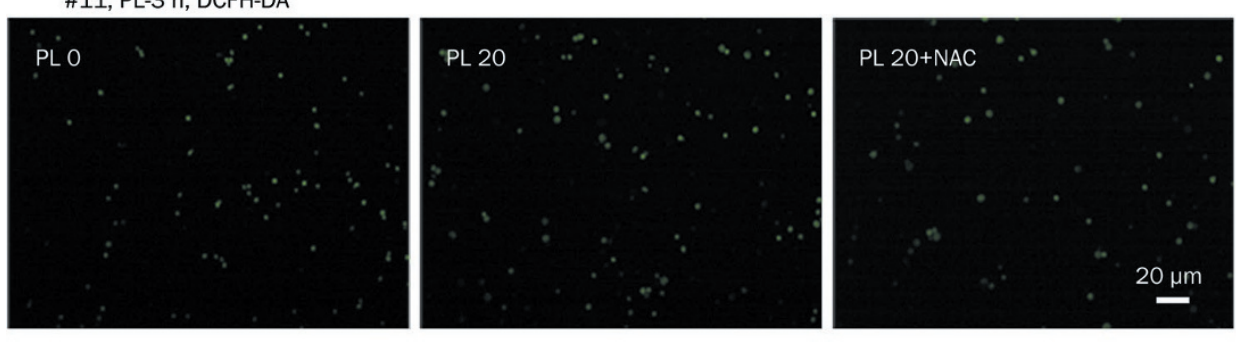
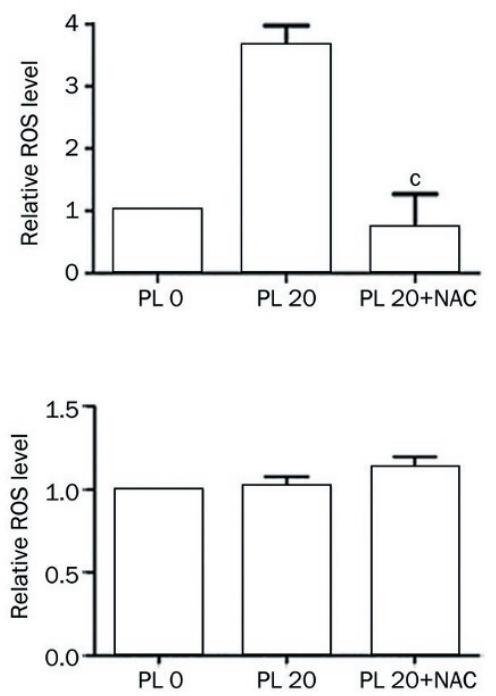

D
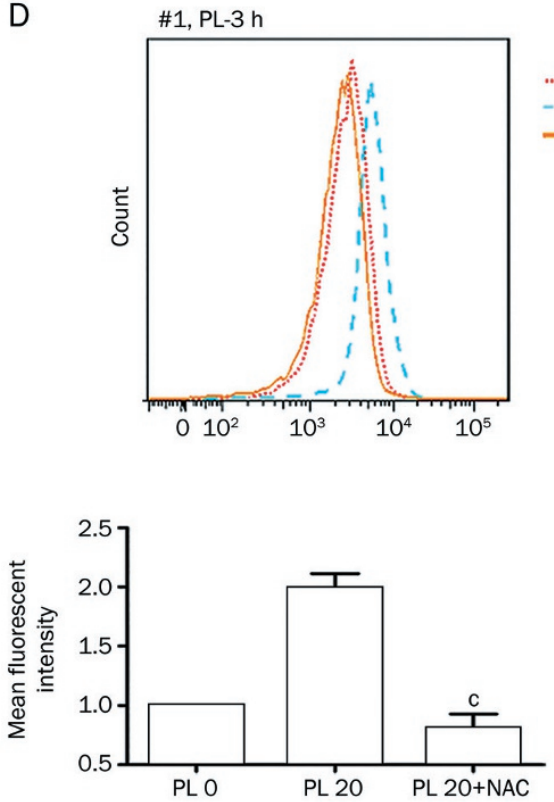

E
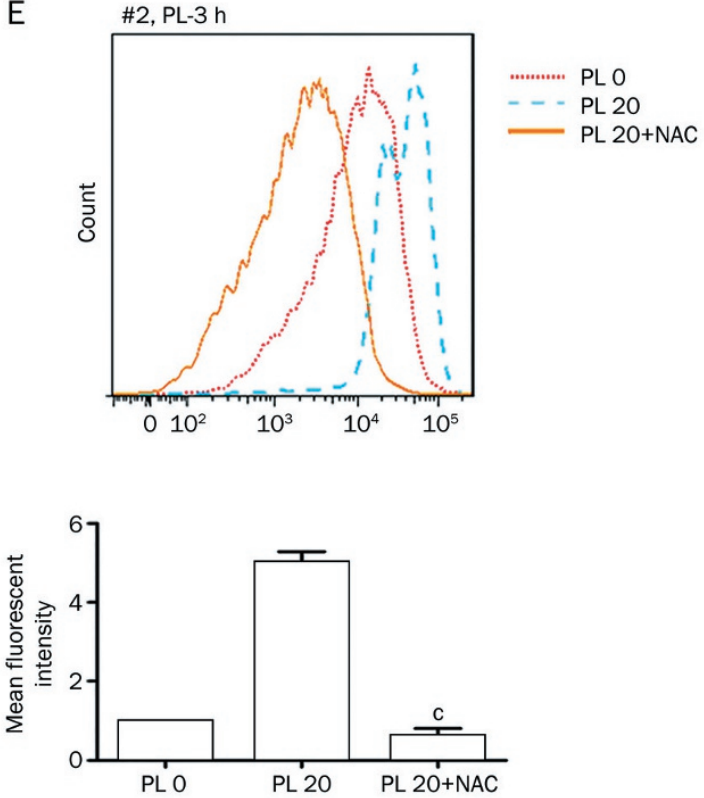

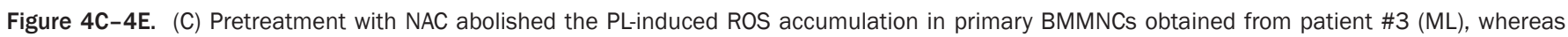

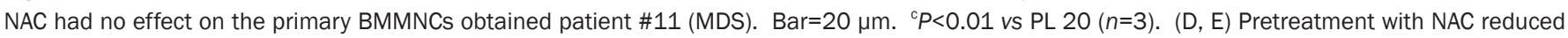

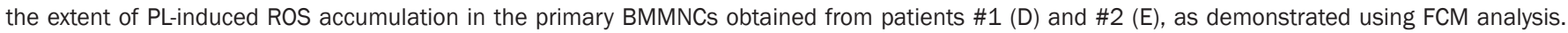
The lower panel shows the results of the statistical analysis $(n=3)$. ${ }^{c} P<0.01$ vs PL 20 .

$24 \mathrm{~h}$ of treatment with PL at 10 and $20 \mu \mathrm{mol} / \mathrm{L}$, in a dosedependent manner (Figure 5B). Clearly, autophagic signaling pathways were activated in PL-treated primary BMMNCs. Treatment with NAC or with a p38- or a JNK- inhibitor (SB or $\mathrm{SP}$, respectively) differentially ameliorated the effects of PL on the induction of Beclin-1 expression and LC3B activation (Figure 5B). Consistent with these results, Western blotting analysis demonstrated that the levels of both p-p38/p38 and $\mathrm{p}-\mathrm{JNK} / \mathrm{JNK}$ were greatly increased after various periods (1, $3,6,12$, and $24 \mathrm{~h}$ ) of PL treatment compared with the levels at $0 \mathrm{~h}$ (Figure 5C). In the PL-treated BMMNCs obtained from an MDS patient, only delayed and transient p38 activation was detected between 6 and $12 \mathrm{~h}$ of PL treatment, whereas JNK activation was not observed (Figure 5D). NAC treatment slightly reduced the level of p-p38 activation after $3 \mathrm{~h}$ of treatment with PL at $20 \mu \mathrm{mol} / \mathrm{L}$ (Figure 5E).

Piperlongumine induced cell death or apoptosis in primary human myeloid leukemia cells via p38/JNK activation

Finally, we examined whether the PL-induced ROS accumulation and p38/JNK activation contributed to the PL-mediated cytotoxicity in primary human BMMNCs. NAC treatment 
A

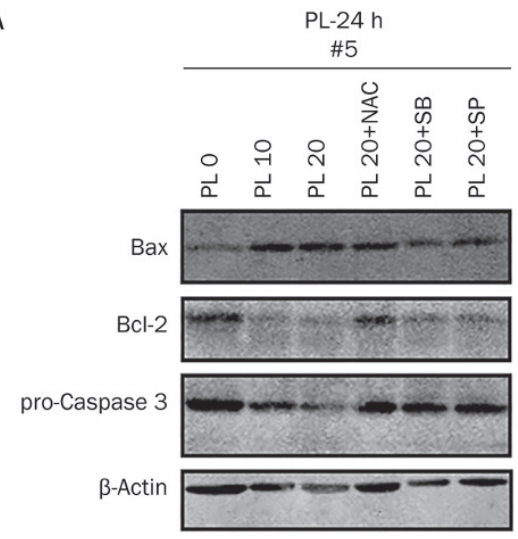

C
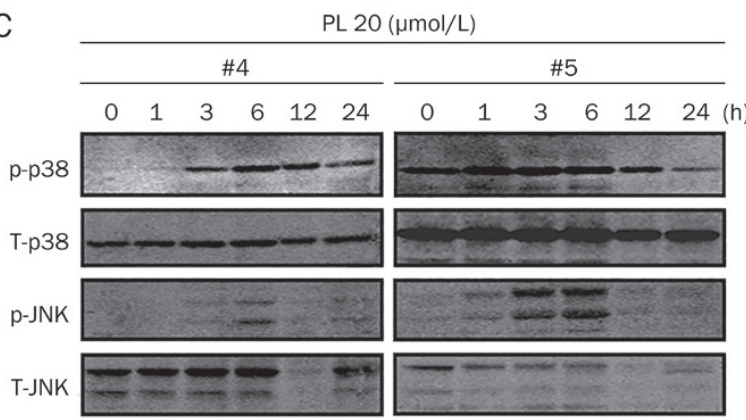

B

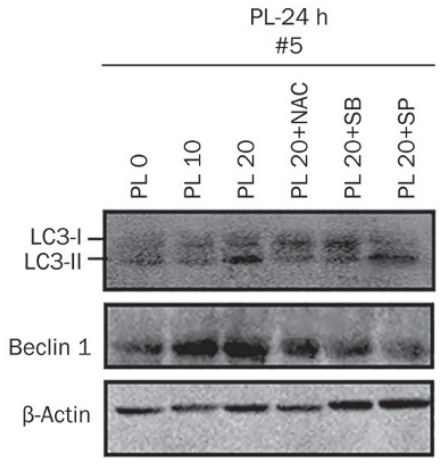

D
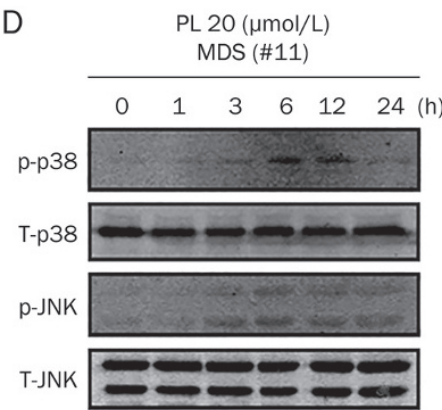

E

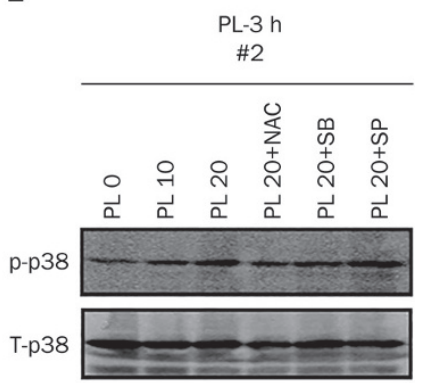

Figure 5. Piperlongumine activated apoptotic and autophagic cell death pathways in primary human myeloid leukemia cells via ROS accumulation or p38/JNK activation. (A) Representative Western blots demonstrating the levels of Bax, Bcl-2, and pro-caspase-3 in PL-treated primary BMMNCs obtained from patient \#5. The cells were treated with PL alone $(0,10$, or $20 \mu \mathrm{mol} / \mathrm{L}), \mathrm{PL}(20 \mu \mathrm{mol} / \mathrm{L})+\mathrm{NAC}(3 \mathrm{mmol} / \mathrm{L}), \mathrm{PL}(20 \mu \mathrm{mol} / \mathrm{L})+\mathrm{SB} 203580$ $(\mathrm{SB}, 10 \mu \mathrm{mol} / \mathrm{L})$ or $\mathrm{PL}(20 \mu \mathrm{mol} / \mathrm{L})+\mathrm{SP} 600125(\mathrm{SP}, 10 \mu \mathrm{mol} / \mathrm{L})$ for $24 \mathrm{~h}$. Equal amounts of total protein were subjected to Western blotting analysis using the designated antibodies. B-Actin was used as the internal loading control. (B) Representative Western blots demonstrating the levels of LC3B and Beclin 1 in PL-treated primary BMMNCs cells obtained from patient \#5. (C) Representative Western blots demonstrating the levels of p-p38/ p38 and p-JNK/JNK in primary BMMNCs obtained from patients \#4 or \#5 at various time points of PL treatment. (D) Representative Western blots demonstrating the levels of p-p38/p38 and p-JNK/JNK in primary BMMNCs obtained from patient \#11 (MDS) at various time points of PL treatment. (E) Representative Western blots demonstrating the levels of p-p38/p38 in PL-treated primary BMMNCs obtained from patient \#2 after $3 \mathrm{~h}$ of treatment with $\mathrm{PL}$ alone or in combination with either NAC $(3 \mathrm{mmol} / \mathrm{L}), \mathrm{SB}(10 \mu \mathrm{mol} / \mathrm{L})$ or $\mathrm{SP}(10 \mu \mathrm{mol} / \mathrm{L})$. The Western blot shown here is representative of three independent experiments yielding similar results.

ameliorated the PL-mediated reduction of the viability of the BMMNCs obtained from all of the patients with AML or CML (patients \#1-\#9), as determined using the MTT assay (Figure 6A). Notably, NAC almost completely reversed the cytotoxicity of PL in the BMMNCs obtained from patient \#2 but had little effect on the BMMNCs obtained from patient \#1 (Figure $6 \mathrm{~A})$. SB or SP treatment also partially reversed the cytotoxicity of PL (eg, in the BMMNCs obtained from patients \#3 and \#7) but was less effective than NAC treatment (Figure 6A). Consistent with these results, co-treatment using SB or SP and PL ameliorated the level of PL-induced apoptosis in the BMMNCs obtained from patient \#2 (Figure 6B). Treatment with SB or SP significantly reduced the intracellular ROS levels in the PL-treated BMMNCs, as determined using fluorescence microscopy of the BMMNCs obtained from patient \#3 (Figure 6C) and using FCM analysis of the BMMNCs obtained from patient \#2 (Figure 6D), whereas neither SB treatment or $\mathrm{SP}$ treatment affected the ROS level of the BMMNCs obtained from the patient with MDS (patient \#11). This evidence sug- gested that $\mathrm{p} 38 / \mathrm{JNK}$ activation could enhance the PL-induced accumulation of ROS in primary human BMMNCs obtained from AML/CML patients not in those obtained from MDS patients.

\section{Discussion}

In the present study, we demonstrated that piperlongumine can effectively kill primary BMMNCs (mainly myeloid leukemia cells) obtained from patients with AML or CML. PL activated both apoptotic and autophagic signaling pathways via its effects on ROS, p38, or JNK. Clearance of ROS or suppression of $\mathrm{p} 38 / \mathrm{JNK}$ activation lessened the cytotoxicity of PL in primary myeloid leukemia cells.

We discovered that PL exerted a specific cytotoxic effect in myeloid leukemia cells but not in non-leukemic cells. PL significantly reduced the viability of BMMNCs obtained from all 9 of the ML patients ( 6 with AML and 3 with $\mathrm{CML}, \mathrm{IC}_{50}<20$ $\mu \mathrm{mol} / \mathrm{L}$ ) but not that of the BMMNCs obtained from the MDS patient. Each patient was randomly selected from those with 
A
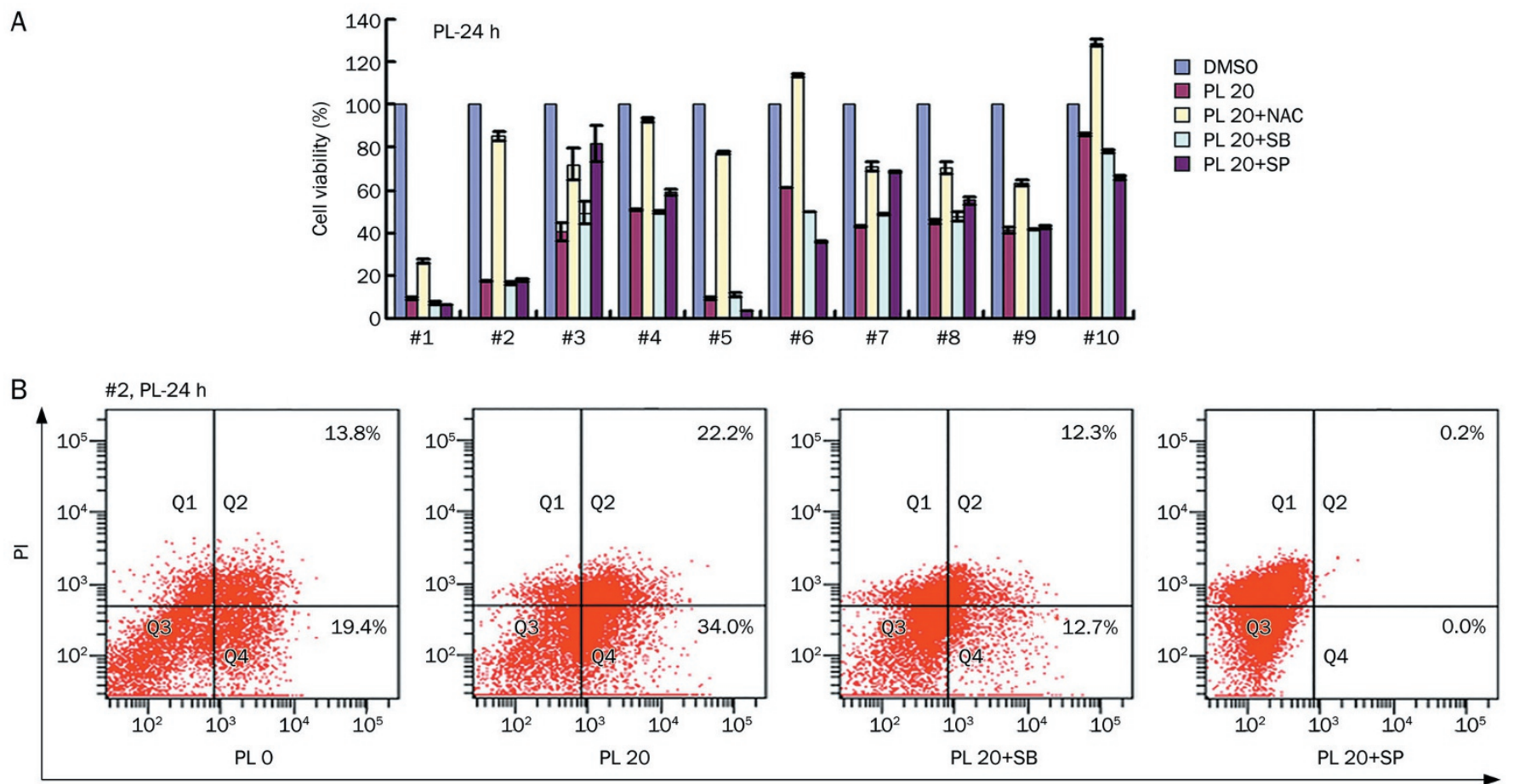

Annexin V-FITC

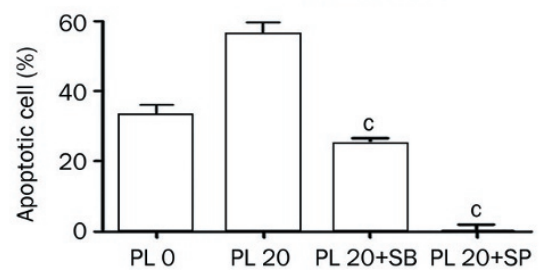

Figure 6A-6B. Piperlongumine induced cell death or apoptosis in primary human myeloid leukemia cells via p38/JNK activation. (A) Effect of NAC or p38/JNK inhibitors on the PL-induced cell death of primary BMMNCs obtained from patients. Cell viability was evaluated using the MTT assay. Primary BMMNCs obtained from patients \#1-\#10 were treated with PL $(20 \mu \mathrm{mol} / \mathrm{L})$ alone or in combination with NAC $(3 \mathrm{mmol} / \mathrm{L})$, SB (10 $\mu \mathrm{mol} / \mathrm{L})$ or SP (10 $\mu \mathrm{mol} / \mathrm{L})$ for $24 \mathrm{~h}$. $n=3$. (B) Effect of SB $(10 \mu \mathrm{mol} / \mathrm{L})$ or SP $(10 \mu \mathrm{mol} / \mathrm{L})$ on the PL-induced apoptosis of primary BMMNCs obtained from patient \#2. The cells in Q2+Q4 represent apoptotic cells. ${ }^{c} P<0.01$ vs PL 20 group.

primary or relapsed $\mathrm{ML}$, and none was excluded. Our results suggested the generally efficacy of PL in ML therapy. In our primary cultures of BMMNCs, all types of myeloid mononuclear cells, including leukemia cells, were present, closely mimicking the actual cellular components and cellular environment in vivo. Notably, at $20 \mu \mathrm{mol} / \mathrm{L}$, PL had almost no effect on the viability of the BMMNCs from the MDS patient, suggesting that PL did not kill normal BMMNCs or abnormal myeloid non-leukemic cells.

Previous studies demonstrated the specific cytotoxic effect of PL in various cancer cell lines but not in normal primary cells obtained from animals, including hematopoietic cells ${ }^{[26]}$. Therefore, the cytotoxicity of PL in the primary BMMNCs obtained from patients with ML was largely a specific effect of PL in myeloid leukemia cells. The differential cytotoxic effects of PL in different myeloid leukemia samples might signify the high level of biological heterogeneity of ML cells and their variable sensitivity to $\mathrm{PL}$ treatment, most likely reflecting the actual therapeutic effects of PL in future cancer treatments ${ }^{[27]}$.
In addition to killing primary ML cells, PL was also effective in killing myeloid leukemia cells from patients with relapsed ML, suggesting that it could be an alternative and safer drug for treating refractory ML or for preventing relapsing ML. Identifying the key parameters that determine the sensitivity of myeloid leukemia cells to PL could further improve the therapeutic effects of PL in ML patients.

PL killed myeloid leukemia cells via different mechanisms. PL clearly induced apoptosis in myeloid leukemia cells, as demonstrated by the increased level of annexin- $\mathrm{V}$ staining and the altered expression of apoptotic proteins, such as Bax, Bcl-2 and caspase-3, consistent with the results of previous studies using various cancer cell lines ${ }^{[28]}$. Because the rate of apoptotic death was not equal to the rate of total cell death induced by PL treatment, other types of cell death must also have occurred in the PL-treated myeloid leukemia cells. Autophagic cell death, another type of programmed cell death, was previously observed in PL-treated cancer cell lines ${ }^{[13]}$. The upregulated expression of Beclin- 1 and LC3B, which are molecular markers 
C \#3, PL-3 h, DCFH-DA
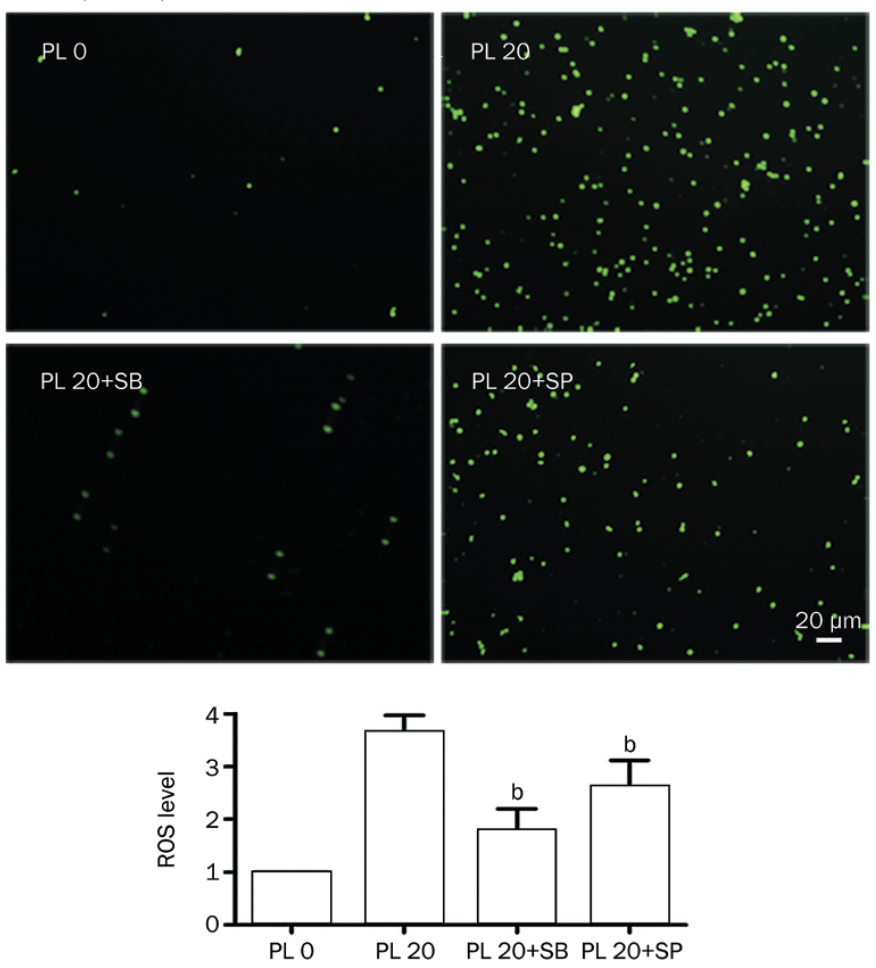

D

\#2, PL-3 h

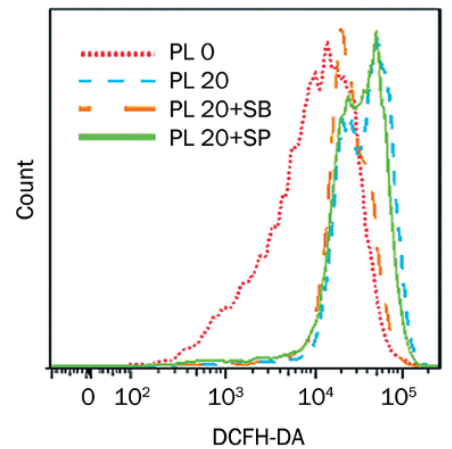

\#11, PL-3 h, DCFH-DA
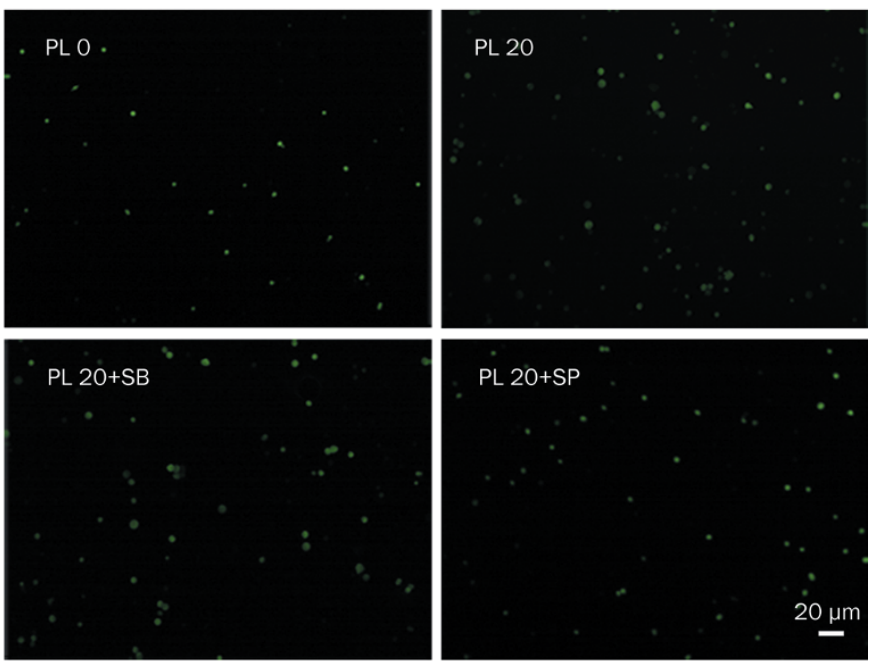

PL 20+SP
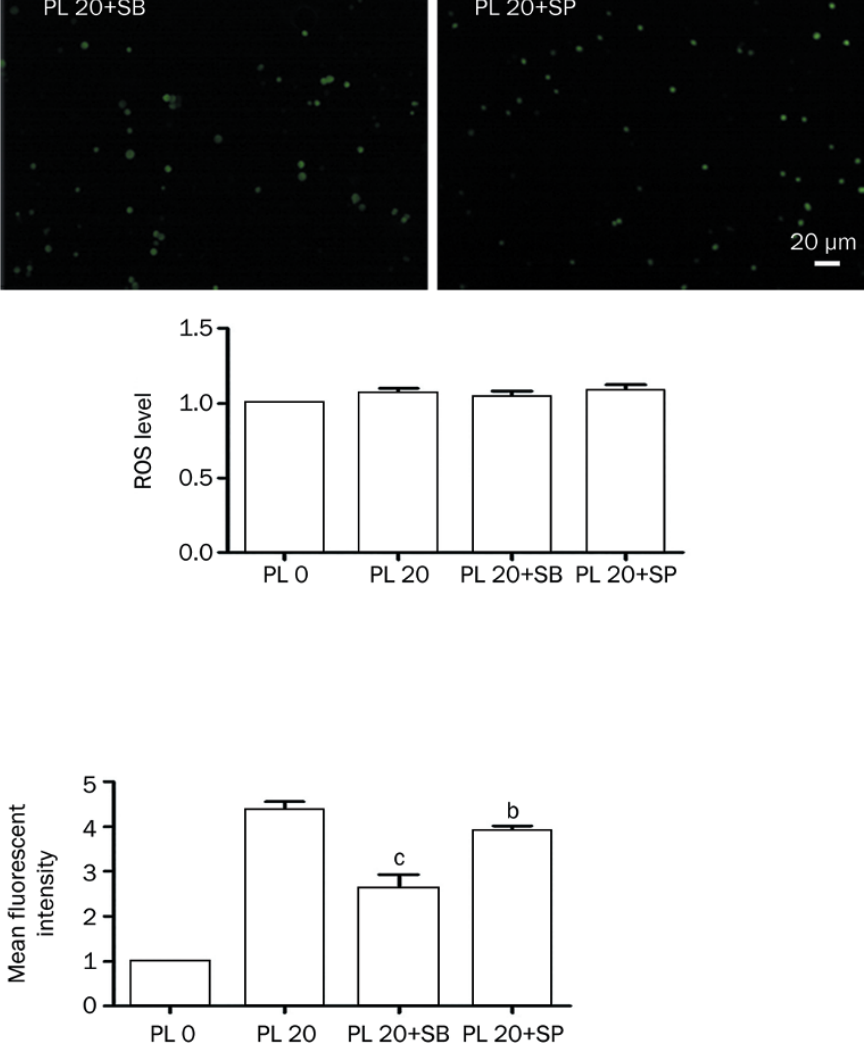

Figure 6C-6D. (C) Effect of SB $(10 \mu \mathrm{mol} / \mathrm{L})$ or SP $(10 \mu \mathrm{mol} / \mathrm{L})$ on the PL-induced ROS accumulation in primary BMMNCs obtained from patients \#3 (ML) or \#11 (MDS). ${ }^{b} P<0.05$ vs PL $20(n=3)$. (D) Effect of SB $(10 \mu \mathrm{mol} / \mathrm{L})$ or SP $(10 \mu \mathrm{mol} / \mathrm{L})$ on the PL-induced RoS accumulation in primary BMMNCs obtained from patient \#2, as determined using FCM analysis. ${ }^{\mathrm{b}} P<0.05,{ }^{\mathrm{C}} P<0.01$ vs $\mathrm{PL} 20$ group.

for autophagic cell death, strongly suggested the occurrence of autophagic cell death in the PL-treated myeloid leukemia cells.

PL possesses diverse biological activities, the underlying mechanisms of which remain elusive. Very recently, it was proposed that PL selectively kills cancer cells but not normal cells by inducing ROS accumulation specifically in cancer cells ${ }^{[10]}$. We previously reported that PL selectively killed glioblastoma cells but not normal astrocytes by inducing ROS accumulation only in glioma cells ${ }^{[12]}$. In primary myeloid leukemia cells (Figure 3) but not primary MDS cells (lower panels, Figure 4C), the intracellular ROS level was also clearly increased. Previous studies demonstrated that treatment with the antioxidant NAC completely abolished the PL- induced ROS accumulation and cell death in many cancer cell lines, including GBM cells ${ }^{[10]}$. In our study, NAC completely abolished the PL-mediated ROS accumulation and effectively reduced the level of PL-induced cell death in all of the ML samples, supporting the concept that ROS accumulation is the major mechanism contributing to the cytotoxicity of PL in the cancer cells obtained from patients. In contrast to the results obtained using cancer cell lines, we found that NAC could only partially reduce the PL-mediated cytotoxicity in several of the ML samples (eg, samples \#1, \#9, Figure 6A).

These results might reflect the complexity of the cellular components and the heterogeneity of cancer cells in vivo. It has been proposed that PL impairs ROS homeostasis by 
interacting with key antioxidant proteins, such as GSTP1 and $\mathrm{CBR}^{[10]}$. However, knocking-down the expression of GSTP1 or CBR1 only reduced the rate of PL-induced cell death in cancer cells ${ }^{[10]}$. This evidence suggests that other mechanisms are involved in the PL-mediated induction of ROS accumulation and cell death. Indeed, PL could exert its cytotoxic effect in cancer cells after its ability to inducing ROS accumulation was abolished $^{[29]}$. We propose that PL kills primary myeloid leukemia cells via both ROS-dependent and -independent mechanisms.

It is well known that ROS accumulation can activate the canonical p38- and JNK-mediated downstream signaling pathways, which contribute to both apoptosis and autophagic cell death ${ }^{[22,23]}$. We previously reported that PL strongly activated p38 and JNK in glioma cells, which contributed to its cytotoxic effect in these cells ${ }^{[12]}$. Wang et al ${ }^{[30]}$ also reported that p38 activation contributed to the PL-induced autophagic cell death in cancer cells. In several of the samples of primary myeloid leukemia cells, p38 and JNK were strongly activated (Figure $5 \mathrm{C})$, and the activation of p38 or JNK contributed to the PLinduced cell death (Figure 6A, and PL-induced the activation of apoptotic and autophagic cell death pathways (Figure 5A and $5 \mathrm{~B})$. However, we also found that inhibiting the p38 or JNK pathway did not affect the PL-mediated cytotoxicity in several other ML samples (Figure 6A). Therefore, both p38/ JNK-dependent and p38/JNK-independent mechanisms were involved in the PL-induced cell death of the myeloid leukemia cells (Figure 7).

We previously demonstrated that NAC completely blocked the PL-induced p38/JNK activation in glioma cell lines, whereas inhibiting p38/JNK activation did not affect the ROS level ${ }^{[12]}$. In primary myeloid leukemia cells, however, ROS accumulation could be alleviated by inhibiting the p38/JNK pathways (Figure 6C), whereas p38 activation could be partially blocked by NAC treatment (Figure 5D). These results suggested a reciprocal ROS and p38/JNK interacting signaling network became active in myeloid leukemia cells upon PL treatment.

\section{Conclusion}

In summary, PL effectively and selectively killed primary myeloid leukemia cells obtained from ML patients via activating both apoptotic and autophagic cell death pathways. ROS/ p38/JNK-dependent and -independent mechanisms were involved in the PL-mediated cytotoxicity in myeloid leukemia cells. PL is likely a potentially safer drug for treating patients with primary or relapsed AML or CML.

\section{Acknowledgements}

This study was supported by funding from the National Natural Science Foundation of China (Grant Nos 81070937, 81172397 and 81471386), Fundamental Research Funds for the Central Universities grant (HUST No 2013ZHYX017) to Xiaoqian CHEN and China Postdoctoral Science Foundation grant (№ 2013M542026) to Feng PAN.

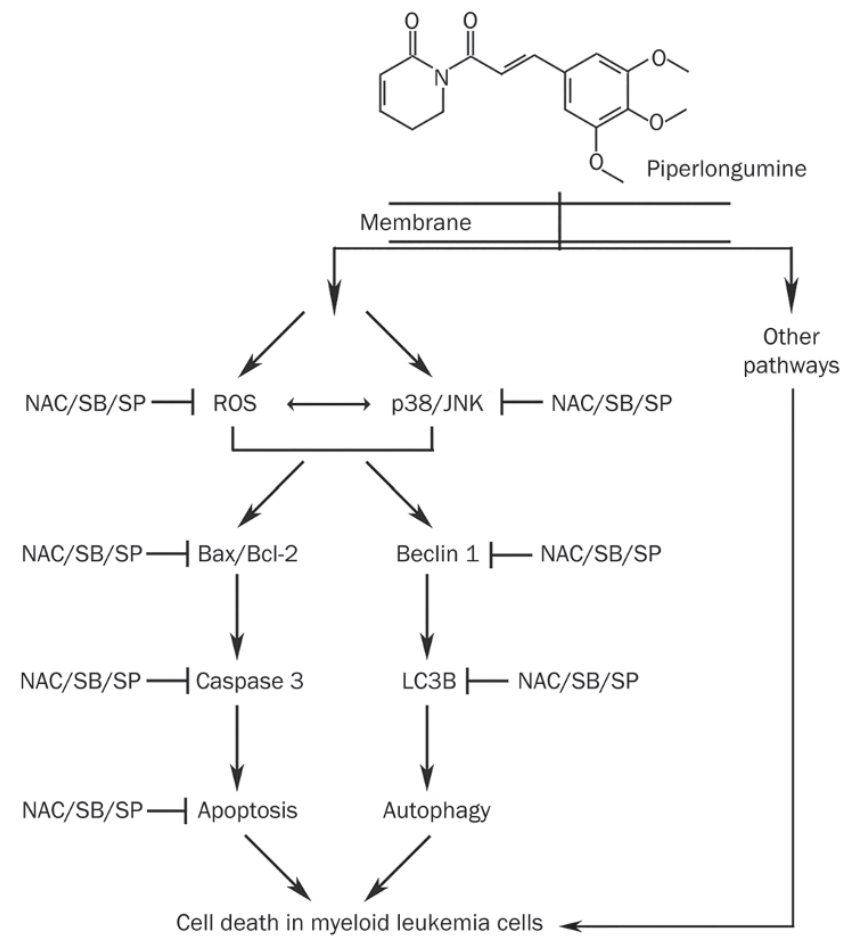

Figure 7. Proposed mechanisms of action of piperlongumine in primary myeloid leukemia cells. Piperlongumine (PL) induced ROS accumulation and activated $\mathrm{p} 38 / \mathrm{JNK}$ and apoptotic/autophagic signaling in myeloid leukemia cells obtained from patients with ML, killing them. Treatment with the antioxidant NAC or with p38/JNK inhibitors SB or SP blocked the PL-activated cell death signaling in primary myeloid leukemia cells, thus preventing their death. In addition, PL appeared to kill myeloid leukemia cells via other pathways that are independent of ROS-p38/JNK signaling.

\section{Author contribution}

Xin-xin XIONG, Ju-mei LIU, Shang-bin YU, and Xiao-qian CHEN designed the experiments; Xin-xin XIONG, Ju-mei LIU, Xin-yao QIU and Feng PAN performed the experiments; Xinxin XIONG, Ju-mei LIU, and Xin-yao QIU analyzed the data; and Xin-xin XIONG and Xiao-qian CHEN wrote the manuscript.

\section{References}

1 Lowenberg B, Pabst T, Vellenga E, van Putten W, Schouten HC, Graux C, et al. Cytarabine dose for acute myeloid leukemia. N Engl J Med 2011; 364: 1027-36.

2 Garcia-Manero G, Faderl S, O'Brien S, Cortes J, Talpaz M, Kantarjian HM. Chronic myelogenous leukemia: a review and update of therapeutic strategies. Cancer 2003; 98: 437-57.

3 Yang DH, Lee JJ, Mun YC, Shin HJ, Kim YK, Cho SH, et al. Predictable prognostic factor of CD56 expression in patients with acute myeloid leukemia with $\mathrm{t}(8: 21)$ after high dose cytarabine or allogeneic hematopoietic stem cell transplantation. Am J Hematol 2007; 82: 1-5.

4 Middeke JM, Fang M, Cornelissen JJ, Mohr B, Appelbaum FR, Stadler $\mathrm{M}$, et al. Outcome of patients with abnl(17p) acute myeloid leukemia after allogeneic hematopoietic stem cell transplantation. Blood 2014; 123: $2960-7$. 
5 Dores GM, Devesa SS, Curtis RE, Linet MS, Morton LM. Acute leukemia incidence and patient survival among children and adults in the United States, 2001-2007. Blood 2012; 119: 34-43.

6 Krug U, Rollig C, Koschmieder A, Heinecke A, Sauerland MC, Schaich $\mathrm{M}$, et al. Complete remission and early death after intensive chemotherapy in patients aged 60 years or older with acute myeloid leukaemia: a web-based application for prediction of outcomes. Lancet 2010; 376: 2000-8.

7 Schwarz M, Kreuzer KA, Baskaynak G, Dorken B, le Coutre P. Imatinib-induced acute generalized exanthematous pustulosis (AGEP) in two patients with chronic myeloid leukemia. Eur J Haematol 2002; 69: 254-6.

8 Shoba G, Joy D, Joseph T, Majeed M, Rajendran R, Srinivas PS. Influence of piperine on the pharmacokinetics of curcumin in animals and human volunteers. Planta Med 1998; 64: 353-6.

9 Wu S, Sun C, Pei S, Lu Y, Pan Y. Preparative isolation and purification of amides from the fruits of Piper longum L. by upright countercurrent chromatography and reversed-phase liquid chromatography. J Chromatogr A 2004; 1040: 193-204.

10 Raj L, Ide T, Gurkar AU, Foley M, Schenone M, Li X, et al. Selective killing of cancer cells by a small molecule targeting the stress response to ROS. Nature 2011; 475: 231-4.

11 Bharadwaj U, Eckols TK, Kolosov M, Kasembeli MM, Adam A, Torres $\mathrm{D}$, et al. Drug-repositioning screening identified piperlongumine as a direct STAT3 inhibitor with potent activity against breast cancer. Oncogene 2014. doi: 10.1038/onc.2014.72.

12 Liu JM, Pan F, Li L, Liu QR, Chen Y, Xiong XX, et al. Piperlongumine selectively kills glioblastoma multiforme cells via reactive oxygen species accumulation dependent JNK and p38 activation. Biochem Biophys Res Commun 2013; 437: 87-93.

13 Veiga-Santos P, Desoti VC, Miranda N, Ueda-Nakamura T, Dias-Filho $\mathrm{BP}$, Silva SO, et al. The natural compounds piperovatine and piperlonguminine induce autophagic cell death on Trypanosoma cruzi. Acta Trop 2013; 125: 349-56.

14 Shrivastava S, Kulkarni P, Thummuri D, Jeengar MK, Naidu VG, Alvala $\mathrm{M}$, et al. Piperlongumine, an alkaloid causes inhibition of PI3K/ $\mathrm{Akt} / \mathrm{mTOR}$ signaling axis to induce caspase-dependent apoptosis in human triple-negative breast cancer cells. Apoptosis 2014; 19: 114864.

15 Randhawa H, Kibble K, Zeng $\mathrm{H}$, Moyer MP, Reindl KM. Activation of ERK signaling and induction of colon cancer cell death by piperlongumine. Toxicol In Vitro 2013; 27: 1626-33.

16 Ginzburg S, Golovine KV, Makhov PB, Uzzo RG, Kutikov A, Kolenko VM. Piperlongumine inhibits NF-kappaB activity and attenuates aggressive growth characteristics of prostate cancer cells. Prostate 2014; 74 : 177-86.

17 Liu QR, Liu JM, Chen Y, Xie XQ, Xiong XX, Qiu XY, et al. Piperlongumine inhibits migration of glioblastoma cells via activation of ROS- dependent p38 and JNK signaling pathways. Oxid Med Cell Longev 2014; 2014: 653732.

18 Li L, Liu QR, Xiong XX, Liu JM, Lai XJ, Cheng C, et al. Neuroglobin promotes neurite outgrowth via differential binding to PTEN and Akt. Mol Neurobiol 2014; 49: 149-62.

19 Halasi M, Wang M, Chavan TS, Gaponenko V, Hay N, Gartel AL. ROS inhibitor $\mathrm{N}$-acetyl-L-cysteine antagonizes the activity of proteasome inhibitors. Biochem J 2013; 454: 201-8.

20 Liu Y, Chang Y, Yang C, Sang Z, Yang T, Ang W, et al. Biodegradable nanoassemblies of piperlongumine display enhanced anti-angiogenesis and anti-tumor activities. Nanoscale 2014; 6: 4325-37.

21 Golovine KV, Makhov PB, Teper E, Kutikov A, Canter D, Uzzo RG, et al. Piperlongumine induces rapid depletion of the androgen receptor in human prostate cancer cells. Prostate 2013; 73: 23-30.

22 Gomez-Lazaro M, Galindo MF, Melero-Fernandez DMR, FernandezGomez FJ, Concannon CG, Segura MF, et al. Reactive oxygen species and p38 mitogen-activated protein kinase activate Bax to induce mitochondrial cytochrome $c$ release and apoptosis in response to malonate. Mol Pharmacol 2007; 71: 736-43.

23 Xiao D, Zeng Y, Prakash L, Badmaev V, Majeed M, Singh SV. Reactive oxygen species-dependent apoptosis by gugulipid extract of Ayurvedic medicine plant Commiphora mukul in human prostate cancer cells is regulated by c-Jun N-terminal kinase. Mol Pharmacol 2011; 79: 499-507.

24 Chen N, Karantza V. Autophagy as a therapeutic target in cancer. Cancer Biol Ther 2011; 11: 157-68.

25 Sato K, Tsuchihara K, Fujii S, Sugiyama M, Goya T, Atomi Y, et al. Autophagy is activated in colorectal cancer cells and contributes to the tolerance to nutrient deprivation. Cancer Res 2007; 67: $9677-$ 84.

26 Bezerra DP, Pessoa C, Moraes MO, Alencar NM, Mesquita RO, Lima $\mathrm{MW}$, et al. In vivo growth inhibition of sarcoma 180 by piperlonguminine, an alkaloid amide from the Piper species. J Appl Toxicol 2008; 28: 599-607.

27 Valk PJ, Verhaak RG, Beijen MA, Erpelinck CA, Barjesteh VWVD, Boer $J M$, et al. Prognostically useful gene-expression profiles in acute myeloid leukemia. N Engl J Med 2004; 350: 1617-28.

28 Lv WW, Qin SN, Chen CQ, Zhang JJ, Ren TS, Xu YN, et al. Isoindolone derivative QSN-10c induces leukemic cell apoptosis and suppresses angiogenesis via PI3K/AKT signaling pathway inhibition. Acta Pharmacol Sin 2014; 35: 625-35.

29 Jarvius M, Fryknas M, D'Arcy P, Sun C, Rickardson L, Gullbo J, et al. Piperlongumine induces inhibition of the ubiquitin-proteasome system in cancer cells. Biochem Biophys Res Commun 2013; 431: 117-23.

30 Wang Y, Wang JW, Xiao X, Shan Y, Xue B, Jiang G, et al. Piperlongumine induces autophagy by targeting $\mathrm{p} 38$ signaling. Cell Death Dis 2013; 4: e824. 